\title{
RESPONSABILIDADE NA AÇÃO TECNOCIENTÍFICA: Contribuições para uma nova relação entre Ciência, Direito e Ética ${ }^{1}$
}

\author{
RESPONSIBILITY IN TECNOSCIENTIFIC ACTION: \\ Contributions to a new relationship between Science, Law and Ethics
}

\author{
Giselle Marie KREPSKY ${ }^{2}$ \\ Artigo recebido em: 18/06/2016 \\ Artigo aprovado em: 19/09/2016
}

RESUMO: Este artigo apresenta uma análise sobre as implicações das ações tecnocientíficas para a ética e o direito. À luz das abordagens propostas por Hans Jonas e Michael Sandel, bem como de suas leituras contemporâneas, aponta limites e possibilidades da bioética e do biodireito na concretização de uma relação responsável do homem com a ciência. A pesquisa que fomentou este texto objetivou compreender como as ações tecnocientíficas, em especial as potencialmente danosas para o homem e a natureza podem ser condicionadas por um agir eticamente comprometido e devidamente regulado pelo direito de forma mais condizente com a complexidade social atual. Conclui que, devido à gradual complexificação social imposta pela própria vivência humana fazse necessária uma revisão no conceito de responsabilidade que norteia tanto bioética quanto biodireito.

${ }^{1}$ Produção científica com auxílio do Edital CAPES nº 002/2013 - DINTER UNISINOS/FURB.

${ }^{2}$ Doutoranda em Direito (UNISINOS). Especialista em Direito Administrativo. Mestre em Educação (Ensino Jurídico). Pesquisadora do Grupo CNPQ Direitos Fundamentais, Cidadania e Novos Direitos atuando nas linhas: Sistema Jurídico e Produção do Conhecimento e Sustentabilidade Socioambiental, Políticas Públicas Ambientais e de Saúde e Ecocomplexidade, Bioética, Biodireito e Direitos Humanos. Professora Titular do Departamento de Direito da FURB. E-mail: gkrepsky@outlook.com 
PALAVRAS-CHAVE: Responsabilidade. Ação tecnocientífica. Ciência. Bioética. Biodireito.

ABSTRACT: Thisarticlepresentsananalysis of theimplications of technoscientific actions for ethics and law. From the approaches proposed by Hans Jonas and Michael Sandel, as well as their contemporary works, this article points to limits and possibilities of bioethics and biolaw of achieving a responsible relationship between man and science. The research which inspired this article had the goal of understanding how technoscientific actions, especially ones which can potentially damage man and nature can be conditioned to act ethically and be regulated by the law in a way which is more suitable to how society currently. It concludes that due to the gradual social complexification imposed by human life itself, it is necessary to review the concept of responsibility which guides bioethics and biolaw.

KEYWORDS: Responsibility. Technoscientific action. Science. Bioethics. Biolaw. 


\section{Introdução}

O homem enquanto ser humano e enquanto cidadão pertencente a uma sociedade complexa precisa refletir e deliberar sobre os limites da intervenção humana sobre as coisas e sobre o humano. Sobretudo, precisa de um paradigma apropriado que possa subsidiar as ações humanas diante da sua capacidade técnica.

Assim, as ações tecnocientíficas ${ }^{3}$, consideradas para este estudo como o entrelaçamento entre a ciência pura e a sua dependência atual da tecnologia e vice-versa, inserem-se no campo da liberdade e levam a indagar sobre os limites da autonomia da ciência e sobre qual deve ou pode ser a interferência do direito como regulador social. Dessa forma, duas disciplinas surgem para nortear as escolhas humanas diante da capacidade técnica: a Bioética e o Biodireito. A primeira é terminologicamente proposta em meados da década de setenta e enquanto ramo da filosofia moral ocupa-se dos aspectos morais das ações e das técnicas que eclodiram com o avanço científico-tecnológico, em especial os que envolvem os estudos na área da biologia, incluindo-se aí todos os derivados científicos como a medicina, engenharia genética, biotecnologia e suas relações com a física, a química entre outras especificidades (BARRETTO, 2009). A segunda compreende o arcabouço de normas jurídicas que tratam das implicações biotecnológicas visando à regulação das condutas humanas inerentes a essa seara de atuação social. Sendo assim, o que se percebe é o caráter de complementaridade das duas, uma vez que a bioética irá fornecer o suporte de compreensão ético-moral das normas e sua aplicabilidade.

A exploração destas temáticas merece um tratamento sofisticado na contemporaneidade, sobretudo, porque a ciência já não é mais a portadora das certezas. Ao contrário, ela mesma deve fazer escolhas menos arriscadas para o homem e para o planeta diante das próprias incertezas. Sendo assim, de onde deve partir a imposição de limites para o agir tecnocientífico? Só porque o homem detém o domínio da técnica significa que poderá utilizá-la ilimitadamente? Para ensaiar uma resposta a estas indagações, o artigo traz à

\footnotetext{
${ }^{3}$ Nesse sentido, Dagnino (2008, p. 27) ressalta que: "A ciência não consistiria de pura teoria, nem a tecnologia de pura aplicação, senão que ambas seriam integrantes de redes de cujos nós também faz parte todo tipo de instrumentos, seres e objetos relevantes à atividade que se desenvolve em seu entorno. Os produtos da atividade científica - as teorias - não poderiam então continuar sendo separados dos instrumentos - as tecnologias, inclusive - que participam da sua elaboração".
} 
baila reflexões acerca das relações entre a ética, a ciência e o direito de modo que as ações no campo tecnocientífico possam ser conduzidas para a proteção da natureza humana e não-humana, sem que com isso se deixe de usufruir dos conhecimentos advindos da ciência.

\section{Sociedade complexa e tecnocientífica}

O homem passou do domínio da técnica para se proteger dos perigos a que estava exposto na natureza e que colocavam em risco a sua continuidade, para o aprimoramento da técnica de que dispõe para se proteger dos riscos causados pelo próprio uso da tecnologia dantes experimentada. Um paradoxo causado pela curiosidade e pela capacidade humana. Este cenário demonstra o modelo antropocêntrico no qual a sociedade se constituiu. Ou seja, quando se trata de tecnologia, sempre há uma ação humana que a antecede e voltada para resultados especialmente na condição humana seja de sobrevivência e saúde ou de melhoria humana. Contra todo o perigo oferecido pela natureza, a intervenção antropocêntrica, por meio da tecnologia, alcança resultados dantes impensáveis, que habitavam apenas o campo da ficção científica ou da criação cinematográfica.

No entanto, esse mesmo homem curioso e soberbo de suas conquistas tem que lidar com os riscos que a descoberta e o uso da tecnologia da qual diz ter domínio podem causar a si e à continuidade do gênero humano com as características a ele inerentes. Seja na produção de sementes melhoradas geneticamente para saciar o perigo da fome, ou na intervenção genética do homem sobre o homem para combater os males que acometem a saúde, ou ainda as descobertas nanotecnológicas e o uso oriundo destas habilidades tecnocientíficas, há algo em comum: as decisões humanas ${ }^{4}$.

Para aumentar esta celeuma, não é possível dissociar as relações nada simples entre a ciência, a técnica, a sociedade, a indústria e o Estado. Nem tampouco se pode desconsiderar as intervenções que o sistema econômico

\footnotetext{
${ }^{4}$ Pelo menos numa perspectiva de total domínio do homem sobre a máquina. No entanto, é preciso manter a vista também que o homem procura criar máquinas a sua imagem e semelhança, inclusive com autonomia decisional. E isto, deve, no mínimo, chamar a atenção para os limites das suas invenções, sob o risco de tornarse escravo da tecnologia. Para Morin (2000, p. 109): "Com a tecnologia, inventamos modos de manipulação novos e muito sutis, pelos quais a manipulação exercida sobre as coisas implica a subjugação dos homens pelas técnicas de manipulação. Assim, fazem-se máquinas a serviço do homem e põem-se homens a serviço das máquinas. E, finalmente, vê-se muito bem como o homem é manipulado pela máquina e para ela, que manipula as coisas a fim de libertá-lo".
} 
exerce sobre o modus de produção científica. Ademais, Morin (2000, p. 9) afirma que "a técnica produzida pelas ciências transforma a sociedade, mas, também, retroativamente, a sociedade tecnologizada transforma a própria ciência. [...] mas nem o Estado, nem a indústria, nem o capital, são guiados pelo espírito científico [...]". Até porque, o homem está envolvido pelo imperativo tecnicista que direciona para experimentar tudo o que tecnocientificamente é possível levando a premissa de que se ele pode, deve fazê-lo (HOTTOIS, 2001).

Todas essas ações comprometem o momento presente, mas, sobretudo, direcionam e modificam as perspectivas de futuro da humanidade. Trabalhar com a perspectiva de futuro é deveras complicado para o direito, porquanto defensor da tradição e da segurança jurídica. Mas, se lidar com o futuro é um movimento complexo para o direito, a ciência está num paradoxo temporal. Se por um lado dela é exigido que aja na urgência de descobertas para a manutenção da vida humana por meio de curas a males da saúde ou otimizações de sobrevivência (como as inovações para superação da saturação alimentar do planeta), ou ainda protegendo a vida humana e não-humana da ação técnica antecedente, por outro se lhe exige que seja prudente nas ações preocupando-se com o futuro transgeracional $1^{5}$ e com as possíveis consequências negativas de suas decisões. Aliás, é no tocante ao predizer o futuro e as consequências que podem advir do uso da própria tecnologia que o empenho da ciência deve ser reforçado. O uso da ciência para a prospecção do futuro deve, pois, ser maior do que o seu esforço despendido nas invenções. O que, paradoxalmente, acaba por exigir um saber muitas vezes ainda nem disponível, diante da imprevisibilidade e da incapacidade de prever as futuras invenções (JONAS, 2011).

Nesse sentido Hottois (1990, p. 66) esclarece que:

Essa imprevisibilidade - que torna o futuro ao mesmo tempo absolutamente opaco e totalmente aberto - provém, em última análise, do facto do futuro ser, em grande medida, colocado doravante sob a égide do aperfeiçoamento e do possível tecnocientífico, sendo o modo de evolução da tecnociência da ordem de construção, da invenção, em resumo, da prática criadora que nenhuma teoria prevê.

${ }^{5}$ A geração futura ou vindoura não se trata apenas de filhos ou netos, mas de toda a humanidade futura. Cf. HOTTOIS, Gilbert. Gerações Vindouras. In: HOTTOIS, Gilbert; MISSA, Jean-Noël. Nova enciclopédia da bioética: medicina, ambiente, biotecnologia. Lisboa: Instituto Piaget, 2001, p. 389. 
Assim, o dilema que se impõe ao pensamento moral diante de um futuro incerto e da própria incerteza científica é: como conciliar a não ação por precaução protegendo a continuidade da existência humana e do planeta com a exigência de agir utilizando-se das técnicas possíveis também para garantir a existência futura? Ou seja, tanto o agir quanto o não agir podem de alguma forma afetar o futuro, posto que hoje já não é mais possível dizer que o planeta se autogerencie como no passado. Essa previsão toda se assevera com a complexidade social.

Então, as implicações dessas decisões por vezes confundem-se, constituindo uma linha tênue entre os efeitos positivos e negativos, para os quais uma perspectiva bioética pode lançar um olhar mais acurado e norteálas. Nesse sentido, a principal ação que exige maior atenção da bioética, diz respeito às possibilidades de alteração no gênero humano. As possibilidades da ciência genética trazem uma promessa de um futuro melhor que trazem consigo indissociáveis dilemas éticos.

É exatamente nesta seara que se enquadram a promessa e o dilema da engenharia genética. A promessa pode atender às expectativas colocadas anteriormente, mas o dilema é que as descobertas ainda recentes desta área podem permitir que ocorra uma manipulação da própria natureza humana. Nesse sentido, Sandel (2013) questiona se seria moralmente aceito que se alterarem os músculos geneticamente para melhorar o desempenho no esporte, suplementar a memória e aprimorar as habilidades, melhorar o humor cotidiano, ou ainda escolher o sexo dos filhos, mas também as suas especificidades físicas e porque não mentais. Afinal, é ético que se deseje isto e realmente se faça? Diante da incerteza científica, é razoável que se enverede por tais escolhas tecnocientíficas? Qual a perspectiva de intervenção futura com a reinserção de espécies no sistema que encontra resiliência para harmonizar a vida? Qual o futuro das espécies recuperadas diante do risco de anomalias e defeitos congênitos? Todas estas questões mostram como uma possibilidade de ação aparentemente simples a primeira vista, facilmente apresenta dilemas sob os quais se deve prospectar e que se intensificam progressivamente quanto maiores são os anseios sociais e as habilidades inventivas do homem.

Porém, e voltando-se para a intervenção na natureza humana, é preciso ressaltar que o que é tratado com naturalidade pela ciência, até porque comporta metodologia e dimensões próprias, não pode ser transportado deliberadamente para a sensação humana. Isto ocorre porque os cientistas acabam por reduzir o 
humano a mera biologicidade, excluindo tudo o que de humano externo a isto caracterize o humano. E nesse sentido, a ética deve intervir não só nas limitações da ação científica, mas, sobretudo, de forma crítica, incluindo todas as dimensões do ser humano em meio a esta pretensão científica (JUNGES, 1999).

Ante o despreparo ético da sociedade, Sandel questiona como se pode lidar com a perspectiva da clonagem caso a tecnologia seja aprimorada ao ponto de não se ter riscos maiores do que o de uma gestação natural. Seria aceitável que se gerasse um filho idêntico ao que morreu ou que tivesse o mesmo código genético de um cientista? $\mathrm{O}$ autor apresenta argumentos e contra-argumentos nas questões tidas como problemáticas para a moral. No caso da clonagem humana reprodutiva, se desejada e permitida, o que de imediato se vislumbra como afetada é a questão da autonomia e liberdade da criança gerada. Mas a autonomia não responde às inquietações morais advindas de outras questões de intervenção genética humana, como por exemplo, o melhoramento genético para si e por meio do qual não haveria consequências prévias para outras gerações. Assim, Sandel (2013) destaca que o dilema moral mais complexo aflora quando se passa da cura das doenças para o melhoramento daquilo que é dado pela natureza, principalmente para um posicionamento acima da média geral natural. Muito mais do que apenas um refinamento estético, o que vem sendo vislumbrado é uma intervenção genética de modificação e melhoramento de músculos, memória, características físicas, entre outras. Nesse tocante, não há que se falar em perda de autonomia, mas, ao contrário, na exacerbação dela. É aqui que vão se concentrar os esforços da bioética, pois se está no limite “[...] de uma era na qual a ciência e suas aplicações práticas deixaram de contentar-se em lidar com o mundo natural como se encontra criado, e passaram pretender alterar a própria natureza" (BARRETTO, 2013). Caracterizando, assim, a evidente passagem do conhecimento das coisas do mundo para a alteração delas somando-se a um desejo de determinar e controlar o futuro testando o alcance da tecnociência.

Outro direito fundamental que parece ser afetado pelas perspectivas tanto da cura quando do melhoramento genético é o da igualdade. Para Sandel (2013), isto pode ser vislumbrado a partir do momento que eventuais tecnologias não estejam à disposição de pessoas carentes, mas tão somente de quem possua condições financeiras para usufruir dos avanços e das curas. Se de alguma forma já soa perturbador o fato de que aos pobres seja negado o acesso à tecnologia, tal perturbação se estende às opções que a comunidade 
científica faz dedicando esforços ao melhoramento em detrimento de uma busca pela cura de doenças tão somente.

Esses problemas ocorrem porque "Quando a ciência avança mais depressa do que a compreensão moral [...] homens e mulheres lutam para articular o seu mal-estar" diante das possibilidades biotecnológicas e das reflexões morais suscitadas e o desejo de usufruir dos resultados (SANDEL, 2013, p. 22). De fato, as questões que envolvem o melhoramento genético vão além da implicação no exercício de direitos básicos como autonomia, liberdade, justiça e igualdade se analisados isoladamente e sem um fundamento norteador, posto que a questão que antecede não deveria ser tão somente a de como o homem lidará com estas possibilidades e suas implicações morais, mas, sobretudo, se ele deve desejar isto.

Se por um lado há certa urgência nas respostas científicas para os males da saúde ou para a possível privação alimentar diante da escassez a que pode se submeter o planeta, por outro, o ser humano insatisfeito com suas limitações diante da vivência pós-moderna e complexa que lhe exige sempre mais perfeição e, estimulado por uma obsolescência programada, exige da ciência uma aceleração produtiva por vezes maior do que sua capacidade de produzir novos conhecimentos. Um paradoxo progressivo que sujeita o homem ao uso de tecnologias que produzem riscos que precisam ser evitados por meio de novas tecnologias. Desejos estes muitas vezes complementados por uma oferta mercadológica audaz.

De toda sorte, é preciso decidir mesmo diante da incerteza. Mas a sociedade que outrora confiava cegamente na racionalidade dos especialistas da ciência, agora se depara com uma margem de desconfiança. Isso coloca o homem diante de uma missão: refletir sobre os desejos e anseios e sobre o que se espera para o futuro e decidir com base na precaução necessária diante da incerteza científica. Ademais, a ciência alcançou patamares de especialização que dificultam ainda mais as escolhas sociais. É o que Jonas (2011) chama de "o preço do progresso científico".

Ainda no campo das especificidades, há limitações da própria contribuição interdisciplinar. Isto para falar no menos exigível, uma vez que as questões colocadas pela ação tecnocientífica implicam numa necessária percepção transdiciplinar dos fenômenos para nortear uma melhor decisão. Pode-se observar como alguns campos do conhecimento humano são escolhidos em detrimento de outros para refletir as questões bioéticas. Especialmente as 
áreas da medicina e das ciências biológicas norteiam boa parte das decisões, esquecendo-se de que a filosofia deveria ser chamada a contribuir para as escolhas humanas nesta seara. Até porque, delegar as decisões no âmbito da pesquisa apenas para os cientistas retira a devida reflexão moral e ética da ação, deixando apenas ao âmbito da técnica a própria reflexão moral. Neste sentido, revela-se surpreendente como a Comissão Nacional de Ética em Pesquisa do Brasil (CONEP) 6 é composta atualmente. Dos 31 integrantes, 10 são médicos, 9 são representastes da área da saúde, 4 da área de exatas e naturais e entre outras áreas, verifica-se apenas 1 filósofo, na qualidade de suplente ${ }^{7}$. No total, verificase uma carência de representação nas áreas humanas e sociais, muito embora sua perspectiva de atuação seja transdisciplinar. Isso sem sombra de dúvidas reflete no caráter da regulamentação e nas diretrizes das pesquisas.

De acordo com Barretto (2013), é neste campo que o direito assume papel relevante devendo buscar fundamentos para as normas por ele produzidas e interpretadas/aplicadas em uma argumentação moral. É preciso um caminho orientador para a tomada de decisões calcada em bases éticas sólidas, já que, apenas a regulação positivista não dará conta destes dilemas e, de outro norte, as perspectivas da bioética sem regulação serão mero diletantismo filosófico.

\section{Bioética e biodireito no contexto das ações tecnocientíficas}

O grau de sofisticação das inúmeras inovações científicas advindas da segunda metade do século passado trouxeram enormes desafios e grandes transformações nas ciências naturais e humanas, especialmente nas áreas da medicina, biologia (com suas múltiplas especializações), biotecnologia e também na ciência do direito, provocando o início de um movimento de repensar crítico de muitos de seus institutos, os quais já não davam conta dos extraordinários, instigantes e particulares problemas que se apresentam no âmbito da pós-modernidade.

\footnotetext{
${ }^{6}$ A CONEP tem como principal atribuição o exame dos aspectos éticos das pesquisas que envolvem seres humanos. Como missão, elabora e atualiza as diretrizes e normas para a proteção dos sujeitos de pesquisa e coordena a rede de Comitês de Ética em Pesquisa das instituições. Cabe a CONEP avaliar e acompanhar os protocolos de pesquisa em áreas temáticas especiais como: genética e reprodução humana; novos equipamentos; dispositivos para a saúde; novos procedimentos; população indígena; projetos ligados à biossegurança com participação estrangeira. Conforme CONEP. Disponível em: <http://conselho.saude.gov.br/Web_comissoes/conep/index.html>. Acesso em: 01 ago. 2015.

${ }^{7}$ Cf. BRASIL. Comissão Nacional de Ética em Pesquisa. Membros CONEP. (on-line). Disponível em: <http:// conselho.saude.gov.br/Web_comissoes/conep/index.html> Acesso em: 01 set. 2016.
} 
Como decorrência lógica destes ensinamentos do passado, surgiu a necessária reaproximação do direito dos seus fundamentos éticos e morais, na direção da proteção e resguardo dos valores e direitos essenciais da pessoa humana. Esta matriz de pensamento ganhou força com a Declaração Universal dos Direitos do Homem de 1948 - principal fonte de legitimação da bioética - cujos valores passaram a permear as mais diversas áreas do conhecimento humano. Para Hottois (2001, p. 112) “a filosofia dos direitos do homem iriam tornar-se progressivamente uma fonte de inspiração múltipla para uma parte importante da reflexão bioética", abrindo deste modo um caminho para que, direta ou indiretamente, as discussões em torno da bioética abarcassem em um futuro próximo, a vida, tomada esta em seu contexto mais amplo. Assim, neste complexo cenário tem-se o surgimento da Bioética, ou seja, como decorrência de uma corrente de pensamentos impregnados de grande sensibilidade moral segundo a qual os avanços tecnocientíficos não se traduzem necessariamente em progressos para a humanidade, haja vista que o que se mostra tecnicamente possível, ou mesmo factível do ponto de vista científico, nem sempre é bom, adequado ou necessariamente permissível do ponto de vista moral.

O crescente avanço do grau de complexidade social fez com que a bioética incorporasse uma série de outros temas em seu âmbito conceitual no sentido de avançar para além de uma ética aplicada estritamente ao campo da medicina e abarcar outros campos como a ecoética ou ética ambiental (HOTTOIS, 2001, p. 112). Por esta inflexão, Barretto (2013, p. 277) salienta que a bioética não se apresenta apenas "na teoria acadêmica, mas na prática dos hospitais, nos comitês de Bioética e na formulação de políticas públicas", sempre buscando o estabelecimento de marcos que viabilizem um desenvolvimento consciente e responsável da tecnologia.

Desde sua gênese, a bioética ancora-se em princípios fundamentais e estruturantes: o princípio da beneficência, o princípio da autonomia e o princípio da justiça. Mas a principal crítica feita por Barretto (2013) à racionalidade e aplicabilidade destes princípios é a de que, além de não se mostrarem complementares podem, se tomados separadamente, ser considerados como superior aos demais. Isto porque, cada um considerado em seu contexto privilegia tão somente a um dos agentes envolvidos tornando-se necessário postular por um modelo principiológico de não sobreposição e sim de complementariedade a fim de preservar a 
autonomia, a solidariedade e a justiça.

Para Junges (1999), em sua crítica à bioética principialista, o defeito deste paradigma é o seu ecletismo, que ofusca os fundamentos morais e o raciocínio ético. Ele aponta que existem contradições importantes nos princípios estabelecidos na medida em que o paradigma principialista, para além de estar centrado em uma lógica que se poderia denominar de dedutiva, está baseado em uma ética do dever. Por essa razão, ignora a experiência moral dos sujeitos envolvidos no processo. A atenção às situações particulares e à subjetividade dos indivíduos impõe um paradigma baseado na experiência (casuísmo). Então, o principialismo puro peca por ecletismo, racionalismo e dentologismo. Para um uso adequado dos princípios, é necessário, assim, integrá-los numa antropologia ética unitária além de completá-los com a perspectiva teleológica que se baseia na virtude e na experiência.

Todavia, olhando para os dilemas morais e éticos que eclodem com as ações tecnocientíficas, tais como as expostas anteriormente, verificase que as orientações da bioética mostram-se insuficientes na imposição de limites a tais comportamentos para além da reflexão individual e particular de cada agente moral, posto que, com visto, sua base é prevista sob a forma de princípios. Necessário, pois, que se empregue coercitividade às normas impostas pela bioética sob pena de perderem sua eficácia. Para tanto, é no biodireito que o fundamento moral da bioética encontra sua concretude na regulação social. Então, o biodireito tem por objeto disciplinar implicações jurídicas advindas dos avanços da ciência biomédica, da biologia, e da biotecnologia aplicada aos seres humanos e, por extensão, a toda a matéria viva incluindo as animais e as plantas (CASABONA, 2001).

$\mathrm{O}$ biodireito nasce e se desenvolve não somente como uma resposta regulatória da conduta humana em forma de aportes teóricos, doutrinários, legislativos e jurisprudenciais que se pretendiam adequados aos novos desafios que se apresentavam, mas, sobretudo, como decorrência e desdobramento lógico dos dilemas gerados pelas novas fronteiras exploradas pela bioética, sua principal fonte motriz. Em uma interface complementar e integrativa com a bioética, torna-se o biodireito um poderoso instrumento de reflexão e ação no sentido da recuperação da dimensão axiológica, ética e moral do agir humano frente aos desafios e provocações trazidos pela complexa realidade tecnocientífica. 
Dessas constatações surgem algumas contribuições do biodireito para o enfrentamento das questões apontadas no contexto da tecnociência. Assim, vale ponderar a necessidade de se recuperar a noção de responsabilidade situando-a em definitivo no espaço da moralidade, criando com isso condições para uma reformulação da teoria da responsabilidade com os aportes e contribuições da teoria da justiça, da teoria moral e da teoria do direito. Esta noção deve se desenvolver em uma dimensão social e política objetiva - inserida por isso no contexto da sociedade - que compreenda o conceito de Estado Democrático de Direito, no qual esta nova teoria da responsabilidade estabeleça sua legitimação moral, ética e jurídica em um ambiente de complementaridade em que estão inseridos, igualmente, a bioética e o biodireito (BARRETTO, 2013).

Nesse sentido, Hottois (2001) mostra o evidente e total esgotamento dos modelos institucionais clássicos (contrato, família e propriedade) da ciência do direito - baseados na lógica da igualdade formal, privatista e individualista do estado liberal burguês do século XVIII - para o enfrentamento dos hipercomplexos e multifacetados problemas e desafios apresentados pela tecnociência da pós-modernidade e dos desafios ético-filosófico-morais deles decorrentes, e, por outro lado, a absoluta necessidade do estabelecimento de uma nova ordem jurídica que de conta das demandas exibidas pela sociedade tecnocientífica.

As características claramente entrópicas da realidade social pósmoderna no campo da tecnociência, forçam a ciência do direito a se reposicionar dogmática e principiologicamente para além de seu viés utilitarista/ positivista. Esta realidade impõe ao direito, por um lado, em um movimento de repensar crítico, a superação de seus paradigmas clássicos, e, por outro, o preenchimento do vazio ético-filosófico gerado por esta realidade do ponto de vista moral, jurídico ou político através da concepção de uma nova dimensão da responsabilidade que reflexione acerca dos avanços na esfera do conhecimento científico e tecnológico - e as implicações dele decorrentes - em uma dimensão diversa das tradicionais noções de ética e responsabilidade.

\section{Exigência de uma nova responsabilidade para o agir tecnocientífico}

As complexidades oriundas da tecnociência e as modificações nas relações sociais, além de proporcionarem uma forma diferente de se encarar a 
autonomia e a liberdade transpondo essencialmente o campo da individualidade para a coletividade, fazem com que seja repensado também o conceito de responsabilidade a fim de que seja mais apto a responder ou, pelo menos, ancorar as condutas humanas.

É nesse sentido que Hans Jonas propõe uma ética que seja mais condizente com as complexidades criadas pelo homem, posto que, a ética clássica já não mais serve para este tempo. Isso por dois motivos essenciais: primeiro porque a ética clássica não abarca as questões relativas ao mundo não humano (ambiente, animais e tudo que possa ser afetado pelo homem), segundo porque ela se preocupa apenas com o tempo presente (JONAS, 2011). Evidente, pois, que não há como se pensar numa perspectiva de responsabilidade que não esteja diretamente implicada com o futuro e com o direito que o humano tem de preservar a identidade de humano enquanto gênero e vivendo em um ambiente equilibrado e, sobretudo, possível.

Aliás, não é por outro motivo que o texto constitucional brasileiro é absolutamente diretivo quando em seu artigo 225 prevê que: "Todos têm direito ao meio ambiente ecologicamente equilibrado, bem de uso comum do povo e essencial à sadia qualidade de vida, impondo-se ao poder público e à coletividade o dever de defendê-lo e preservá-lo para as presentes e futuras gerações". Assim, qualquer atribuição de sentido a ser feita em sua aplicação deve levar em consideração a proposta de uma responsabilidade ética adequada a este tempo e ao tempo futuro. E mais, ela deverá nortear todas as ações diretas e indiretas do agir tecnocientífico, mas, substancialmente, direcionar aqueles a quem incube a tarefa de gestão coletiva, ou seja, todas as esferas do poder (legislativo, executivo e judiciário).

É por isso que Jonas (2011) propõe a substituição dos imperativos éticos do passado, incluindo o mais expoente deles, o imperativo kantiano que prevê que o homem deve agir de forma que a sua ação possa ser transformada em uma lei universal. Em um horizonte mais abrangente e estendido temporalmente, Jonas assevera que o homem deve agir de tal forma que os efeitos da sua ação sejam compatíveis com a permanência de uma vida humana autêntica. Esse imperativo mostra-se muito apropriado, uma vez que a margem de imprevisibilidade gerada pela tecnociência faz surgir um grau de comprometimento mais elevado para com o agir presente. Esse agir deve estar comprometido com muito mais do que apenas a possibilidade de continuidade das gerações do ponto de vista físico, mas também com a possibilidade de 
permanência de uma identidade humana em sua essência.

No entanto, esta não é tarefa fácil, pois se pode questionar como é possível a responsabilidade no tempo presente para com algo que não aconteceu, ou que, apenas está no campo de possibilidade. Nesse tocante, Hottois (2001) salienta que a ideia de responsabilidade para com o futuro não é isenta de inúmeros obstáculos. É difícil que haja o comprometimento com gerações que existirão muito além da existência humana de hoje, com as quais não terá nenhum contato ou implicação direta. Seres que irão viver apenas daqui a décadas, séculos ou milênios. Assim, se de alguma forma já não era tarefa fácil agir de acordo com o imperativo Kantiano, agora, deve-se se sensibilizar com o dever de agir de forma muito mais cautelosa e com uma alteridade igualmente redimensionada no tempo e no espaço.

E aqui vale destacar novamente o papel da ciência ao subsidiar as ações devendo trabalhar no âmbito da previsão ideal. Ela terá que ser mais ampla para se aproximar de um diagnóstico provável de futuro. O horizonte que esse saber científico em meio a essa dinâmica complexa, onde o homo faber quer e tem o poder de dominar a tudo e a todos, tem que ser em longo prazo. Porque o prognóstico na era da técnica em que os alcances podem ser catastróficos, não se pode conformar em predizer apenas o hoje, por mais que essa seja uma tarefa árdua diante da incerteza do futuro (JONAS, 2011).

Nesse tocante, a perspectiva da precaução de Jonas (2011, p. 204) se radicaliza e é trabalhada na heurística do medo ante a qual vale considerar que: "A profecia do mal é feita para evitar que se realize [...]", pois não havendo saber suficiente para fazer a projeção, que se assuma como prevenção a projeção mais catastrófica, qual seja, a que poria em risco a própria humanidade do humano, e sua existência futura.

Há que se retomar a discussão sobre os limites do uso da tecnologia e do próprio desenvolvimento tecnológico bem como ponderar sobre o que se assumirá de responsabilidade. Assim, Jonas faz um contraponto entre a irresponsabilidade da crença em milagres científicos e de outro lado a irresponsabilidade de se basear na predição de que o homem se adapta a tudo. Isso seria jogar-se na incerteza da possibilidade de o homem se adaptar ou não às transformações. As questões aí devem superar a ponderação de se o homem se adaptará ou não para o novo, mas: “A que o homem deveria se adaptar? [...] A que o homem dever ser forçado ou autorizado a se adaptar?". E tudo isso faz permear de novo a questão sobre que tipo de homem se pretende ser no 
futuro. Então a responsabilidade do homem público se estende também nesse nível (JONAS, 2011, p. 206).

A promessa da tecnologia moderna se converteu em ameaça para o homem. Em que pese ter sido concebida para a felicidade humana, a submissão da natureza, que agora se estende a própria natureza do homem, conduziu ao maior desafio já posto pela sua própria ação (JONAS, 2011). Uma nova dimensão de responsabilidade, portanto, não só é possível como necessária, na medida em que, se por um lado os avanços da tecnologia se tornaram uma solução para muitos dos problemas humanos, por outro, transformaram-se igualmente em fontes de risco e dano concreto e principalmente abstrato.

Desse modo, os dilemas éticos e morais relacionados com o desenvolvimento e o uso da biotecnologia ganharam relevo na medida em que ficavam cada vez mais evidentes os problemas, as inadequações e a insuficiência dos modelos e institutos clássicos do direito - sobretudo da teoria clássica da responsabilidade e da justiça, fundada nos ideais liberais da propriedade privada, autonomia individual e noção do ser humano como titular absoluto de direitos universais inalienáveis - e da gestão destas novas transformações de singular complexidade e risco.

Resulta desta realidade a necessidade de uma reflexão moral sobre a ciência que conduza ao desenvolvimento do conhecimento científico a partir de ditames racionalmente construídos pela comunidade humana, tendo como pressuposto uma perspectiva ética e que estimule uma reflexão apta a superar a dimensão transindividual dos problemas e desafios postos pela tecnociência, cujas singulares transformações provocaram, sob o ponto de vista da teoria moral, uma nova abordagem dos atos sociais e de sua responsabilização jurídica.

Para Barretto (2013), as questões éticas da contemporaneidade - do ponto de vista da tecnociência - passam hoje a transcender o espaço das relações puramente transindividuais para abarcar os problemas globais, nos âmbitos coletivos e difusos da ecologia, da natureza humana e do futuro da espécie, provocando um esgotamento da noção de responsabilidade até então adotada para a solução dos conflitos, que deve agora projetar-se para além da dimensão puramente individual. Dessa forma, as angústias éticas decorrentes das possíveis intervenções tecnocientíficas apontadas inicialmente merecem ser respondidas à luz das proposições da bioética e do biodireito, mas, mormente, com base nos preceitos relativos a uma responsabilidade para com o futuro. 


\section{Conclusão}

Ao se refletir sobre as indagações apresentadas inicialmente, procurouse contextualizar o cenário dos dilemas, desafios e transformações enfrentados pela sociedade tecnocientífica contemporânea em seu percurso passado, presente e futuro. Tendo a bioética como paradigma conceitual de base, buscouse equacionar o grau de complexidade dos dilemas, desafios e transformações apresentados neste âmbito, o esgotamento dos paradigmas clássicos de matriz liberal da ciência jurídica contemporânea no enfrentamento destes desafios, bem como a nova dimensão de responsabilidade apresentada por Hans Jonas enquanto paradigma ético "possível" à civilização tecnológica. Igualmente, salientou-se os apontamentos contundentes de Michael Sandel acerca das consequências da tecnologia sobre o ser humano e seus dilemas éticos dantes impensáveis.

Ao longo do percurso teórico traçado, firmou-se a certeza de quão elevados e desafiadores são os dilemas apresentados pela tecnociência à comunidade contemporânea de forma globalizada, seja pelas dimensões das extraordinárias e singulares transformações que apresenta, por seu elevado grau de sofisticação, pela intensidade das ameaças, riscos e incertezas que enseja ou pelos incomuns desafios que exigem dos campos da ética, da moral e do direito um posicionamento adequado.

As incertezas superam as certezas no mundo da tecnociência. E a complexificação social causada pela própria escolha humana assevera ainda mais o contexto do uso da tecnociência. Assim, a insuficiência de referenciais éticos e morais para a sociedade da alta tecnologia transformou, para a teoria ética, o "novo continente da práxis coletiva" em uma terra de ninguém como afirmou Jonas (2011). Trata-se, pois, de um movimento de superação dos referenciais éticos, morais e jurídicos da modernidade, sobretudo da teoria clássica da responsabilidade, de assumir, frente a esta nova realidade sem precedentes, a responsabilidade pelo futuro da humanidade. Este é o grande desafio.

À nova teoria da responsabilidade contemporânea - e em sua esteira a bioética e o biodireito - portanto, caberá a difícil e desafiadora tarefa de incorporar a dimensão da salvaguarda do futuro da espécie humana em seus postulados teóricos e práticos, como forma de acolher, como sua principal e primordial categoria, o respeito e o resguardo à dignidade da pessoa humana. Respondendo sucintamente as indagações de pesquisa propostas para este debate, é, pois, 
somente a partir da relação complementar da bioética e do biodireito alicerçadas na responsabilidade ética com o futuro que se poderá vislumbrar uma ação tecnocientífica que permita a fruição das habilidades humanas, sem, contudo, que elas se oponham a continuidade da existência de vida no planeta.

\section{Referências}

BARRETTO, Vicente de Paulo. O Fetiche dos Direitos Humanos e outros temas. 2. ed. rev. e ampl. Porto Alegre: Livraria do Advogado, 2013.

Bioética. In: BARRETTO, Vicente de Paulo (Coord.). Dicionário de Filosofia do Direito. São Leopoldo: Unisinos, 2009.

BRASIL. Comissão Nacional de Ética em Pesquisa. Membros CONEP. (on-line). Disponível em: < http://conselho.saude.gov.br/Web_comissoes/conep/index. html> Acesso em: 01 set. 2016.

CASABONA, Carlos Maria Romeo. Biodireito. In: HOTTOIS, Gilbert; MISSA, JeanNoël. Nova enciclopédia da bioética: medicina, ambiente, biotecnologia. Lisboa: Instituto Piaget, 2001, p. 94-98.

DAGNINO, Renato. Neutralidade da ciência e determinismo tecnológico. Campinas, SP: Editora da Unicamp, 2008.

HOTTOIS, Gilbert. O paradigma bioético: uma ética para a tecnociência. Lisboa: Ed. Salamandra, 1990.

Bioética. In: HOTTOIS, Gilbert; MISSA, Jean-Noël. Nova enciclopédia da bioética: medicina, ambiente, biotecnologia. Lisboa: Instituto Piaget, 2001, p. 109114.

Tecnociência. In: HOTTOIS, Gilbert; MISSA, Jean-Noël. Nova enciclopédia da bioética: medicina, ambiente, biotecnologia. Lisboa: Instituto Piaget, 2001, p. 602-606. 
Gerações Vindouras. In: HOTTOIS, Gilbert; MISSA, Jean-Noël. Nova enciclopédia da bioética: medicina, ambiente, biotecnologia. Lisboa: Instituto Piaget, 2001, p. 389-391.

JONAS, Hans. O princípio responsabilidade: Ensaio de uma ética para a civilização tecnológica. Rio de Janeiro: Contraponto, 2011.

JUNGES, José Roque. Bioética: perspectivas e desafios. São Leopoldo: Unisinos, 1999.

MORIN, Edgar. Ciência com consciência. 4. ed. Rio De Janeiro: Bertrand Brasil, 2000.

SANDEL, Michel J. Contra a perfeição: ética na era da engenharia genética. Rio de Janeiro: Civilização Brasileira, 2013. 